Revista de Ciencias Sociales - Número 63 (2013) - Páginas 53-86

Inmigración, multiculturalismo y universalidad de los derechos humanos

\title{
INMIGRACIÓN, MULTICULTURALISMO Y UNIVERSALIDAD DE LOS DERECHOS HUMANOS
}

\author{
IMMIGRATION, MULTICULTURALISM AND THE \\ UNIVERSALITY OF HUMAN RIGHTS
}

CARLOS DORN GARRIDO*

Programa de Doctorado Universidad Carlos III de Madrid

carlosdorn@yahoo.com.ar

\section{Resumen}

El tema central de este artículo concierne acerca del desafío que, para los principios constitutivos de las democracias modernas, tales como libertad, igualdad de derechos y trato, pluralismo y respeto por los valores particulares, lanza el multiculturalismo en el seno de las democracias modernas. Porque, la libertad más relevante de una persona es el derecho a formar su conciencia y personalidad, y de actuar conforme a ellos, lo que involucra aspectos de su ambiente cultural. Sin embargo, algunos de ellos pueden ser considerados contrarios a la ética de los derechos humanos, y dicha situación coloca en peligro la posición de los derechos humanos como una ética universal que impone límites a la aceptación y respeto por las diferencias culturales en sociedades que sostienen la democracia como forma de gobierno y de vida.

\section{Palabras claves}

Libertad, igualdad, pluralismo, multiculturalismo, democracia.

\footnotetext{
* Profesor Dr (c) Universidad Carlos III de Madrid, y Mg. Facultad de Derecho de la Universidad de Valparaíso, Chile. Artículo recibido el 15 de agosto de 2013 y aceptado el 29 de noviembre de 2013.
}

Revista de Ciencias Sociales - Número 63 (2013) - Universidad de Valparáíso - ISSN 0716-7725-Valparáiso, Chile 


\begin{abstract}
The main issue of this article concerns about the defiance against the constitutive principles of the modern democracies, such as freedom, equality of rights and treatment, pluralism and respect for particular values, because of the multiculturalism, which holds our modern societies and democracies. The most basic people's freedom is the right to build his conscience and personality by himself and act according to them, what involves aspects of his cultural environment. However, some of them can be considered opposite to the ethics of the human rights and that situation jeopardizes the stand of them as a universal ethics, which imposes limits for the acceptance and respect of all kind of cultural differences into societies that hold democracy as a way of government and life.
\end{abstract}

\title{
Keywords
}

Freedom, equality, pluralism, multiculturalism and democracy.

\section{Introducción}

El proceso de globalización económica ha dado lugar a una desigual distribución mundial de la riqueza, siendo caldo de cultivo para procesos migratorios masivos, desde países pobres hacia el mundo desarrollado. La incorporación de personas con referentes culturales distintos a los del país de recepción, han dado paso a una ordenación de la sociedad caracterizada por la existencia de un entorno multicultural que desdibuja la otrora y supuesta homogeneidad del Estado-nación.

La heterogeneidad cultural presente en las sociedades democráticas de tradición liberal, representa un desafío a la mantención de la cohesión y paz social, atendido que las normas sobre derechos humanos emplean un lenguaje que expresa una idea que no se agota en lo jurídico, sino que su interpretación cruza dimensiones diversas del conocimiento y entendimiento humano que pueden ser variadas según cual sea el sistema de creencias de una cultura, lo que repercute en la pretensión de universalidad ética de los derechos humanos, inconveniente que se agudiza en las sociedades multiculturales.

Tampoco, es menos cierto que los instrumentos internacionales en materia de derechos humanos, son expresión de un amplio consenso

Facultad de Derecho y Ciencias Sociales - Universidad de Valparaíso - Chile 
sobre la existencia de un sentido nuclear de los derechos y libertades individuales, anclado en la dignidad humana, y que define un marco argumentativo mínimo que limita el proceso de toma de decisiones de las autoridades de un Estado y del modo de relación de la cultura mayoritaria con los grupos culturales minoritarios diversos.

Así expuesto, las normas de derechos humanos presentan una zona de certeza mínima que encierra un significado esencial propio de su rasgo de universalidad y, también, un halo de indeterminación, esto es, una apertura de su contenido que es cerrada por la influencia que ejerce la dimensión cultural de una sociedad, sea mediante la creación y aplicación de normas jurídicas, o, a través de las prácticas sociales de los miembros de las comunidades que integran un Estado.

De acuerdo con lo expuesto, el presente trabajo examina el impacto que la inmigración genera en las democracias liberales, ya que sus valores constitutivos de: tolerancia, pluralismo, laicidad, neutralidad ideológica y religiosa, le hacen proclive, en principio, a respetar el ejercicio del derecho humano básico de ser quién, esto es, la libertad de conciencia. Sin perjuicio, también, de reconocer que un valor material de la democracia es su ethos de compromiso de respeto con el valor ético universal de los derechos humanos, apología que es fuente del conflicto consabido entre la universalidad y la particularidad cultural y, especialmente, aflora cuando se trata de prácticas culturales incompatibles con las exigencias morales derivadas de los derechos humanos.

\section{Libertad de conciencia y dignidad humana}

En el catálogo de los derechos humanos, quizás, la libertad de conciencia sea una de las libertades primarias de primer orden, puesto que se corresponde con el reconocimiento a toda persona de la:

"Facultad para poder escoger o elaborar por sí misma las respuestas que estime conveniente a las interrogantes que le plantea su vida personal y social, de comportarse de acuerdo con tales respuestas y de comunicar a los demás lo que considere verdadero"1.

1. PRIETO, Luis: "La libertad de conciencia", en Constitución y Derechos Fundamentales, Centro de Estudios Políticos y Constitucionales, Madrid, 2004. Pág. 623.

Revista de Ciencias Sociales - Número 63 (2013) - Universidad de Valparáíso - ISSN 0716-7725-Valparaíso, Chile 
Lo anterior conecta a la libertad de conciencia con la dignidad de la persona, en cuya versión moderna se concibe como un valor anclado y comprometido con la emancipación individual fundado en el reconocimiento de un valor intrínseco a la vida humana con independencia de cualquier preferencia externa sea de mérito, económica, intelectual o social que pueda concurrir en un individuo. Esta concepción emancipadora de la dignidad humana tiene su origen en la premisa kantiana: la Humanidad misma es una dignidad ${ }^{2}$.

Si la Humanidad es la fuente de la dignidad significa que el individuo no está en el mundo de las cosas y de los medios, sino que es un fin en sí mismo. El rasgo de Humanidad que justifica el valor intrínseco y superior del ser humano sobre las cosas, Kant lo identifica en su facultad racional, capacidad que le permite elegir libremente su curso de existencia, de acuerdo a sus propias convicciones —ética privada - escapando de las determinaciones del mundo externo.

Así entendido, la concepción kantiana de la dignidad humana hunde sus raíces en la libre autodeterminación del individuo, para elegir su proyecto de vida e implementarlo según sus propias convicciones y creencias, sin injerencias externas que impliquen la imposición de una determinada ética. El respeto a la dignidad humana, entonces, supone obligadamente el reconocimiento del derecho a la libertad de conciencia. El Tribunal Constitucional español recuerda la relación entre la dignidad de la persona y su libertad de conciencia, en los términos siguientes:

"Junto al valor de la vida humana y sustancialmente relacionado con la dimensión moral de ésta, nuestra Constitución ha elevado también a valor jurídico fundamental la dignidad de la persona, que, sin perjuicio de los derechos que le son inherentes, se halla íntimamente vinculada al libre desarrollo de la personalidad — artículo 10_ y a los derechos... a la libertad de ideas y creencias — artículo 16- Del sentido de estos preceptos puede deducirse que la dignidad es un valor espiritual y moral inherente a la persona que se manifiesta singularmente en la autodeterminación consciente y

2. KANT, Immanuel: La metafísica de las costumbres, Madrid, Tecnos, 1994, (Trad. Adela Cortina y Jesús Conill). Pág. 335.

Facultad de Derecho y Ciencias Sociales - Universidad de Valparaíso - Chile 
responsable de la propia vida y que lleva consigo la pretensión al respeto por parte de los demás”’.

Dado lo anteriormente expuesto, la libertad de conciencia protege una esfera de intimidad personal inviolable para con las ideas y creencias que conforman las convicciones y son la base nuclear de la construcción identitaria del individuo. A través de ella el individuo logra reconocerse como un ente consciente de sí mismo y de la alteridad de los otros, capaz de otorgarse prescripciones éticas que condicionan su autodeterminación personal. La libertad de conciencia, así, aparece como un derecho fundamental primordial para el proceso de configuración de la autonomía individual y afirmación de su dignidad.

\section{Libertad de conciencia: objeto de protección y sus dimensiones}

El objeto material de protección de la libertad de conciencia son las convicciones, esto es, aquellas ideas y creencias que forman parte del núcleo de nuestra cosmovisión y de la comprensión de nuestra identidad ${ }^{4}$. Su arraigo profundo en el fuero íntimo del ser constituye su característica central, ya que contribuyen a la formación del yo respondiendo a la pregunta del ¿́quién soy? El vínculo de tales ideas y creencias con la construcción de la identidad personal, es aquello que permite atribuirle la cualidad de convicciones, pues forman parte de la esencia nuclear del individuo definiendo su rasgo identitario. Las convicciones "no son otra cosa que ideas y creencias vividas y sentidas como parte integrante de la propia identidad"

La importancia de enfocar las convicciones, desde la perspectiva de su relación íntima con el yo, radica en el hecho que para su calificación y protección como tal por la libertad de conciencia, sea absolutamente

3. Tribunal Constitucional español, Sentencia 53/1985, 11 de abril, fundamento jurídico $8^{\circ}$.

4. LLAMAZARES, Dionisio: Derecho de la libertad de conciencia I, Libertad de conciencia y laicidad, Civitas, Madrid, 2007. Pág. 22.

5. Ibídem, Pág. 21.

Revista de Ciencias Sociales - Número 63 (2013) - Universidad de Valparáíso - ISSN 0716-7725-Valparáiso, Chile 
indiferente discernir acerca de su naturaleza religiosa o no. Afirmación que, por lo demás es congruente con la interpretación que el Comité de Derechos Humanos de las Naciones Unidas, ha venido realizando al artículo 18.1 de la Declaración Universal de Derechos Humanos:

"El artículo 18 protege las creencias teístas, no teístas y ateas, asimismo como el derecho a profesar cualquier religión o creencias. Los términos creencias o religión deben ser interpretados en sentido amplio. La disposición no se limita en su aplicación a las religiones tradicionales o religiones o prácticas con carácter institucional similar a las tradicionales" ${ }^{\text {. }}$

Quedan, por tanto, fuera del ámbito de garantía de la libertad de conciencia las meras opiniones, puesto que estas son ideas esencialmente provisionales expuestas a ser contrastadas y sustituidas por otras, careciendo del rasgo de certidumbre que acompaña a las convicciones y que integran el foro interno del individuo ${ }^{7}$.

En este orden de ideas, la jurisprudencia de la Corte Europea de Derechos Humanos sobre la interpretación del artículo 9.1 de la respectiva convención, ha contribuido a introducir criterios para discernir entre convicciones y opiniones, ya que su distinción guarda incidencia en la libertad individual que se conculca en caso de afectación de una u otra. A este respecto tiene importancia citar el precedente Campbell y Cosans c. Reino Unido, en cuyo parágrafo 36 señaló:

"El término convicciones en sí misma no es sinónimo de opiniones o ideas, al que hacen referencia el artículo 10 de la Convención que garantiza la libertad de expresión, sino que es más acorde al término creencias que empleado en el artículo 9 que protege la libertad de pensamiento, conciencia y religión y que se aplica a los convencimientos que alcanzan un elevado grado de obligatoriedad, de seriedad, de coherencia y de importancia, y que merecen respeto en una sociedad democrática, no siendo incompatibles con la dignidad de la persona..."

6. Comité de Derechos Humanos de las Naciones Unidas, Observación General 22, Sesión 48, 30 de julio 1993.

7. LLAMAZARES, Dionisio, ob., cit. Págs. 21-22.

8. Corte Europea de Derechos Humanos, Campbell y Cosans c. Reino Unido, No 7511/76 y 7743/76, 25 de febrero 1982.

Facultad de Derecho y Ciencias Sociales - Universidad de Valparaíso - Chile 
Los rasgos de obligatoriedad, seriedad, coherencia e importancia propias de las convicciones, dan cuenta de la inocuidad de cual sea el contenido concreto de la convicción - religioso, filosófico, política o atea-y se realza el hecho de que la diferencia trascendental entre las convicciones y las opiniones viene dado por la relevancia que estas ejercen en la esfera moral o intelectual de la persona desprendiéndose de ellas consecuencias éticas prescriptibles para el comportamiento externo de su titular?.

Lo expuesto hasta aquí acerca de la libertad de conciencia, permite identificar que ésta cuenta con una dimensión interna y otra externa.

La vertiente interna dice relación con la libertad para configurar un sistema propio de creencias que define las máximas éticas de sus decisiones de relación para consigo mismo, los demás y el mundo externo. La cara interna de la libertad de conciencia es una garantía de su nivel más básico en función de la autodeterminación individual, referido a la libre formación de la conciencia, reconociendo la facultad o capacidad para decidir en qué creer o no creer. Es una libertad de elección ilimitada e incoercible ${ }^{10}$ de las creencias e ideas personales cuya vivencia y sentido interno impiden que el Derecho pueda imponer restricciones de tipo alguno.

Por su parte, la dimensión externa de la libertad de conciencia comprende una libertad de acción y comportamiento del sujeto, en conformidad con el código axiológico que se ha otorgado libre y conscientemente. Lo anterior supone reconocer libertad para profesar, expresar o manifestar esas convicciones. Así como libertad para comportarse de acuerdo con sus ideas y creencias, o lo mismo pero $a$ contrario sensu expresa el derecho a no ser obligado a realizar conductas que sean contrarias a su ética privada.

Si bien la dimensión externa de la libertad de conciencia, implica el respeto del derecho a expresar o manifestar las convicciones y a

9. VALERO, Ana: Libertad de conciencia, neutralidad del Estado y principio de laicidad (un estudio constitucional comparado, Ministerio de Justicia (Gobierno de España), Madrid, 2008. Págs. 40-41.

10. Ibídem, Pág. 69.

Revista de Ciencias Sociales - Número 63 (2013) - Universidad de Valparáíso - ISSN 0716-7725-Valparaíso, Chile 
comportarse en conformidad a ellas, tampoco es menos cierto, que a esta libertad de acción no le puede ser reconocida un carácter de derecho absoluto $^{11}$. Su ámbito de eficacia goza de una elasticidad condicionada a la interacción con los demás bienes públicos y derechos fundamentales del resto, siendo indispensable establecer limitaciones a su ejercicio sea porque la manifestación de las creencias pueden ser contrarias en sí misma a la ética pública de mínimos democrática que hace posible, precisamente, el ejercicio de esa libertad ${ }^{12}$. O, también, porque en caso de conflicto entre las convicciones personales, y el cumplimiento de una norma jurídica del ordenamiento objetivo es necesario que prevalezca ésta en aras del principio de igualdad ante la ley. Salvo cuando la ley excepcionalmente prevea que puede haber lugar a una dispensa por vía del derecho a la objeción de conciencia. Siempre y cuando que

11. La Corte Europea de Derechos Humanos, en el asunto Leíla Sahin c. Turquía, asunto $\mathrm{N}^{\circ} 44.774 / 98$, de 10 de noviembre 2005, en su parágrafo 108, reconoce que el pluralismo, tolerancia y apertura son sellos distintivos de una sociedad democrática. Si bien en ocasiones los intereses individuales deben subordinarse a la mayoría, la democracia no significa simplemente que las posiciones de la mayorías deban siempre prevalecer: es necesario que logre un balance que asegure un justo y apropiado trato para las minorías que evite cualquier abuso de posición dominante...si bien los derechos y libertades están garantizados por la Convención y sus Protocolos, también debe aceptarse que los Estados en la finalidad de protegerlos pueden verse en la obligación de restringir otros derechos y libertades, tal como el previsto en el artículo 9 .

12. Los órganos de Estrasburgo inspirados en proteger la democracia como elemento de cohesión dentro de la diversidad europea, justifican la imposición de límites a la libertad de expresión, a pesar de considerarla pieza cardinal de la misma, precisamente por ser necesario para proteger al propio sistema democrático. De este modo, reconocen a los Estados miembros un amplio margen de apreciación en la adopción de las medidas que estimen necesarias para restringir la libertad de expresión cuando entra en conflicto con las premisas básicas del sistema democrático. Dicho criterio se justifica en el holocausto humanitario que sacudió al continente europeo en la Segunda Guerra Mundial, dando lugar a que exista un consenso global acerca de la necesidad de proscribir cualquier forma de apología de la barbarie totalitarista, en Kuhnen c. República Federal de Alemania (No 12194/86, 12 de mayo 1988), la Comisión Europea de Derechos Humanos estimó justificada la condena impuesta al demandante por su intento de restablecer el partido Nacional Socialista.

Facultad de Derecho y Ciencias Sociales - Universidad de Valparaíso - Chile 
se trate de una contrariedad a convicciones tan arraigadas cuya infidelidad a las mismas es vivida como una traición a sí mismo ${ }^{13}$, aunque hay que considerar ciertas matizaciones que serán examinadas más adelante.

\section{Presupuestos de la libertad de conciencia: laicidad, neutralidad del Estado, pluralismo, tolerancia y democracia}

La protección dispensada por la libertad de conciencia a la expresión de la autonomía tanto para formar la conciencia decidiendo aquellas convicciones que definen la identidad personal, y el derecho a su exteriorización a través de conductas conforme a ellas, son rasgos que permiten, además de afirmar el estatus de la libertad de conciencia como derecho fundamental, relacionar su fuente de vitalidad y riqueza en el contexto de una sociedad que experimenta y vive el pluralismo como un valor positivo. Entendido el pluralismo como:

"Una seña de identidad de las sociedades libres donde todas las diferentes formas de vida y pensamiento tienen derecho a expresarse libremente, sin que ninguna pueda considerar que está en posesión de una verdad absoluta y excluyente de las demás"14.

Aunque como advierte Giovanni Sartori el hecho que "la variedad y no la uniformidad, el discrepar y no la unanimidad, el cambio y no el inmovilismo, sean "cosas buenas", son creencias de valor que emergen con la tolerancia, que se adscribe al contexto cultural del pluralismo y que tiene que expresar una cultura pluralista que haga honor a su nombre" ${ }^{15}$.

13. LLAMAZARES, Dionisio, ob., cit. Pág. 24.

14. FERNÁNDEZ, Eusebio: "La declaración de 1948. Dignidad humana, universalidad de los derechos y multiculturalismo", en Dignidad humana y ciudadanía cosmopolita, Instituto de Derechos Humanos Bartolomé de las Casas, Dykinson, Madrid, 2001. Pág. 67.

15. SARTORI, Giovanni: La sociedad multiétnica. Pluralismo, multiculturalismo, extranjeros e islámicos, Taurus, Madrid, 2003. Pág. 32.

Revista de Ciencias Sociales - Número 63 (2013) - Universidad de Valparáíso - ISSN 0716-7725-Valparaíso, Chile 
Así dicho, la libertad de conciencia es un derecho fundamental que solamente puede florecer en las sociedades democráticas, puesto que pluralismo y la tolerancia son sus valores constitutivos. Los que, además, son presupuestos para la emergencia de la oportunidad para el diálogo y encuentro en el mar de la heterogeneidad cultural, promoviendo un marco para la cohesión y paz social. Característica que la diferencia de las otras formas de gobierno inspiradas en la prevalencia de la autoridad y preferencia por la uniformidad e inmovilismo.

La relación intrínseca entre libertad de conciencia, pluralismo, tolerancia y democracia, da cuenta de la dimensión institucional que desempeña esta libertad en un sistema democrático cuya base fundamental es la existencia y promoción de una opinión plural. Y, naturalmente, la consecución de tal objetivo demanda la realización efectiva de la libertad de ideas y creencias. En este sentido, el Tribunal Constitucional español considera que:

"Sin la libertad ideológica consagrada en el artículo 16.1 de la Constitución, no serían posibles los valores superiores de nuestro ordenamiento jurídico que se propugna en el artículo 1.1 de la misma para constituir el Estado social y democrático de Derecho que dicho precepto se instaura... Las libertades que garantiza el artículo 16.1 exceden del ámbito personal por su dimensión institucional y porque significan el reconocimiento y la garantía de la opinión pública y libre y, por tanto, del pluralismo propugnado por el artículo 1.1 de la Constitución, como uno de los valores superiores de nuestro ordenamiento" ${ }^{16}$.

La jurisprudencia de la Corte Europea de Derechos Humanos, a propósito de la interpretación del artículo 9 de la convención, reitera constante y uniformemente que:

“En el marco del significado y espíritu de la convención, la libertad de pensamiento, conciencia y religión es uno de los fundamentos de una sociedad democrática, toda vez que el valor del pluralismo es indisociable a toda sociedad democrática, depende de ella"17.

16. Tribunal Constitucional español, Sentencia 20/1990, 15 de febrero, Fundamentos jurídicos $3^{\circ}$ y $4^{\circ}$.

17. Corte Europea de Derechos Humanos, Bayatyan c. Armenia, No 23.459/93, 7

de julio 2011, párrafo 118. En igual sentido: Kokkinakis c. Grecia, No 14.307/

Facultad de Derecho y Ciencias Sociales - Universidad de Valparaíso - Chile 
La valoración del pluralismo en una sociedad democrática exige, además, como condición sine qua non neutralidad ideológica y religiosa del Estado, inhibiéndose de favorecer cualquier ideología, sea religiosa o de otra índole, ya que es el único modo de asegurar condiciones de igualdad de trato en el ejercicio de este derecho fundamental. Frente a la pluralidad ideológica el Estado debe asumir una neutralidad negativa, ya que consustancial a una democracia es la observancia estricta del principio de igualdad de trato en el espacio de lo público. Esta vertiente de la neutralidad ideológica, en relación con el ejercicio de la libertad de conciencia, se traduce para el Estado en las prohibiciones siguientes de:

a. No interferir en el fuero interno, lugar donde se forma la conciencia personal en un constante proceso de internación, afirmación o cambio de las ideas y creencias que dan forma a la identidad personal y al libre desarrollo de la personalidad y;

b. No impedir a las personas a que puedan conformar sus conductas a sus propias prescripciones éticas derivadas de sus convicciones personales. El Estado queda impedido de adoptar cualquier decisión de autoridad que signifique una forma de coacción, directa o indirecta, a un ciudadano en razón de su ideología o cosmovisión. Por ejemplo, el poder público no puede adoptar sanciones ni, tampoco, imponer un trato discriminatorio.

Esta interpretación del principio de igualdad y neutralidad ideológica es la aproximación que se hace desde un liberalismo ortodoxo, que considera la consecución de la igualdad, únicamente, por la vía de abstraer al sujeto de sus condiciones particulares: su referente cultural. Sin embargo, tal solución ha probado ser insatisfactoria para tratar los problemas derivados de sociedades heterogéneas, tal como quedó demostrado en la lucha de los derechos civiles de la población de color, la lucha del movimiento feminista, de la comunidad homosexual y, de mayor actualidad, del reconocimiento de un derecho a la diferencia por las poblaciones inmigrantes.

88, 25 de Mayo 1993, párrafo 31; Buscarini y otros c. San Marino, No 24.645/94, 18 de febrero 1999, párrafo 34; y Leyla ${ }^{a}$ ahin c. Turquía, No 44774/98, párrafo 104.

Revista de Ciencias Sociales - Número 63 (2013) - Universidad de Valparáíso - ISSN 0716-7725-Valparaíso, Chile 
A consecuencia de lo anterior, un ala del liberalismo considera la necesidad de tratar de manera discriminatoria las diferencias lingüísticas, culturales etc., a fin de mejorar ética y funcionalmente las reglas del juego liberal democráticas ${ }^{18}$. Se instala, así, la comprensión de que la actitud del Estado no puede limitarse a una posición de contemplación o pasividad frente a la pluralidad ideológica de las sociedades, ya que la igualdad material de tratamiento en el ejercicio de la libertad de conciencia, exige un rol activo de los poderes públicos que asegure sus condiciones reales y efectivas de ejercicio, removiendo los obstáculos que puedan obstar a esa igualdad. Lo cual es coherente con el deber del poder público de facilitar el ejercicio del derecho a la libertad de conciencia, eliminando las desigualdades reales que impidan el ejercicio pleno e igual del derecho fundamental frente al resto de las otras ideologías.

La acción pública no se contrapone con la neutralidad ideológica de un Estado liberal, sino que la reafirma ya que lo que se persigue no es la identificación del Estado con una ideología en concreto. Sino que al contrario, es una acción orientada a crear las condiciones de igualdad real que permitan a todos, independiente de sus creencias, ejercer en forma efectiva y segura su libertad de conciencia. Es un reconocimiento de que el contexto real donde se ejercen los derechos y libertades a menudo distorsionan la igualdad formal y abstracta de las prescripciones normativas. Por lo demás, esto cobra pleno sentido en las sociedades multiculturales, donde existe una ideología dominante o mayoritaria siendo necesaria la acción estatal para asegurar a las minorías su libertad de conciencia, y, con ello la vigencia de la seña de identidad de la democracia denominada pluralismo.

Con justa razón, Dionisio Llamazares ${ }^{19}$ identifica la fuente de vida y desarrollo del pluralismo en la libertad de conciencia, ya que

18. JAUREGUI, Gurutz: "Inmigración y diversidad cultural en la era de la globalización. De la multiculturalidad a la interculturalidad”, en Alberdi Bidaguren, Jokin y Goizueta Vértiz, Juana (coords.), Algunos retos de la inmigración en el siglo XXI, Marcial Pons, Madrid, 2008. Pág. 276.

19. LLAMAZARES, Dionisio: Educación para la ciudadanía democrática y objeción de conciencia, Colección Conciencia y Derecho, Dykinson, Madrid, 2010.

Pág. 58.

Facultad de Derecho y Ciencias Sociales - Universidad de Valparaíso - Chile 
tomarse en serio este derecho fundamental implica, necesariamente, aceptar como un valor positivo, en una sociedad democrática, la existencia de una diversidad de identidades culturales sean individuales o colectivas. Lo anterior unido a la relación intrínseca entre la libertad de conciencia con la dignidad humana en su vertiente de libre formación y desarrollo de la personalidad, conduce al reconocimiento del derecho a la diferencia en igualdad de derechos. Su concreción, con cotas importantes de cohesión y paz social, exige tener presente que la tolerancia es una consecuencia obligada del pluralismo, con lo que la salvaguarda del pluralismo en una sociedad demanda una actitud de respeto de los ciudadanos para con aquellos con creencias o convicciones diferentes. La tolerancia como condición del pluralismo, es un principio informador del ordenamiento jurídico y un mandato jurídico de respeto del derecho a la diferencia dirigido directamente a los ciudadanos e indirectamente a los poderes públicos. Lo cual se traduce en una exigencia dirigida a los ciudadanos para con los otros, a los grupos frente a los otros e incluso a éstos para con sus miembros, a fin de respetar la dignidad, la personalidad y las decisiones en conciencia del otro, y para con los grupos con creencias o convicciones diferente, implica la obligación del reconocimiento del derecho de los otros a la existencia en condiciones de igualdad bajo un mismo ordenamiento jurídico igualmente válido para todos ${ }^{20}$. De este modo, la tolerancia más que una virtud moral, es un principio jurídico que salvaguarda la existencia y florecimiento del pluralismo, imponiendo exigencias de comportamiento para los ciudadanos y colectivos, que se manifiestan tanto en el deber de respeto de los diferentes, y de aceptación de las críticas incluso personales aunque siempre con el límite del insulto o las expresiones que afecten negativamente la dignidad personal ${ }^{21}$.

Sin embargo, el solo principio de tolerancia es insuficiente sino esta acompañado de la garantía institucional de la laicidad del Estado y de los poderes públicos, que exige la no identificación con principios

20. LLAMAZARES, Dionisio: Derecho de la Libertad de Conciencia, Vol. I, Cuarta Edición, Thomson-Reuters, Madrid, 2011, p. 344.

21. Ibídem. Págs. 344-345.

Revista de Ciencias Sociales - Número 63 (2013) - Universidad de Valparáíso - ISSN 0716-7725-Valparáiso, Chile 
o convicciones alguna de sus ciudadanos, salvo con los valores comunes que definen al Estado Social y Democrático de Derecho. La importancia del principio de laicidad del Estado radica en que no es posible en una sociedad la existencia de un pluralismo que sea fruto del ejercicio pleno de la libertad de conciencia, si no existe laicidad del Estado. Puesto que, el Estado no es cualquier sujeto de Derecho sino se trata de uno que está atribuido de poder de mando y coacción sobre los individuos, por lo que su identificación con una creencia o ética privada - que no sea la de los valores comunes- entraña un peligro no sólo para la libertad de conciencia sino para el resto de los derechos humanos básicos vinculados a su ejercicio.

La laicidad del Estado significa la no confusión entre Estado y religión, lo que se traduce en secularización del Estado y desestatalización de la religión, lo que entraña dos cosas: neutralidad del Estado y su separación de las Confesiones religiosas. La segunda es condición para la primera.

La neutralidad implica que el Estado debe ser imparcial respecto a las convicciones y creencias, sean religiosas o no, de sus ciudadanos, ya que es la única garantía de asegurar el pleno respeto de la igualdad y, en consecuencia, de la libertad de conciencia. Por lo que, está obligado a conceder el mismo trato tanto a quienes tienen creencias religiosas como a quienes no la tienen ${ }^{22}$. La neutralidad "es una consecuencia obligada del principio de igualdad en libertad; de otra manera sería imposible valorar de otra manera a los ciudadanos que tienen ideas y creencias religiosas de los que no las tienen, o a los que tienen unas de los que tienen otras"23.

Y, la separación del Estado frente la Iglesia y viceversa, implica una emancipación del poder político respecto de cualquier doctrina o credo religioso, con lo que el Estado y sus poderes públicos no se subordinan a confesión alguna ni a sus doctrinas, evidenciando una no confusión de lo político y lo religioso. Todos presupuestos de la separación que son esenciales para la neutralidad del Estado y ergo para

22. Ibídem. Págs. 346-350.

23. Ibídem. Pág. 351.

Facultad de Derecho y Ciencias Sociales - Universidad de Valparaíso - Chile 
el ejercicio pleno de la libertad de conciencia y la existencia de un pluralismo con igualdad de derechos, dentro de una sociedad democrática ${ }^{24}$.

Si bien, el pluralismo en democracia conlleva la aceptación de la diversidad cultural en igualdad de derechos. También, la salvaguarda del pluralismo exige de la estructura social y jurídico-política la necesidad de establecer lo que es común con carácter imprescindible ${ }^{25}$, el que es un presupuesto fundamental para una convivencia pacífica y cohesionada. La identificación del Estado con un mínimo común ético en modo alguno puede considerarse una quiebra del principio de laicidad del Estado. Sino que una ética pública de mínimos es signo de una versión de democracia que alberga y respeta la existencia de éticas privadas contrapuestas, puesto que la neutralidad ideológica no implica una de tipo ético del Estado. Por lo demás, se trata de una ética que define un marco de referencia para la convivencia libre, igualitaria y pacífica de la diversidad de las conciencias particulares nacidas en el mosaico de las sociedades multiculturales.

El significado e importancia que esta ética pública tiene para las sociedades democráticas, surge del examen de la debacle moral experimentada en la Segunda Guerra Mundial, lo que dio paso a una refundación de la democracia sobre un acervo axiológico forjado en el compromiso y promoción hacia un orden cohesionado en torno a los valores de la dignidad de la persona, respeto a los derechos humanos y paz social lograda conforme a los principios de igualdad, justicia, pluralismo y de solución pacífica de los conflictos sociales. Surge, así, una versión de democracia que supera la consideración estrictamente formal de mero procedimiento de adopción de decisiones, derivando en una que integra un contenido sustantivo de hondo calado ético que define un mínimo irreductible dentro del cual debe desarrollarse la actividad pública y la convivencia social, según se examinará más adelante.

24. Ibídem. Págs. 353-354.

25. DE LUCAS, Javier: "Multiculturalidad e inmigración: la política de igualdad", en Álvarez Yágüez, Jorge y Lago Peñas, Santiago (eds.), La convivencia plural: derechos y políticas de justicia, Ediciones Bellaterra, Barcelona, 2009. Pág. 72.

Revista de Ciencias Sociales - Número 63 (2013) - Universidad de Valparáíso - ISSN 0716-7725-Valparáiso, Chile 
En síntesis, la existencia del derecho a la diferencia en plena igualdad de derechos, exige del Estado la más exquisita neutralidad en relación con los valores diferenciales que garanticen la igualdad de todos los ciudadanos, sin discriminación alguna en razón de sus creencias, y a defender y proteger la observancia del respeto del diferente de parte de todos ellos, pero siempre y cuando las diferencias no sean contradictorias con los valores compartidos como comunes ${ }^{26}$. No obstante lo anterior, el Estado está obligado a defender y promocionar determinados valores comunes aceptados como tales en el pacto constitucional, que sobre la base de la dignidad de la persona humana $\mathrm{y}$ de los derechos que le son inherentes, del respeto de las diferencias no contradictorias con los valores comunes y de los principios de convivencia democrática, son fuente del mínimo común ético aceptado por el Derecho y que se denomina ética pública.

Por lo tanto, el Estado debe guardar neutralidad respecto de los valores diferenciales de una sociedad, pero frente a los valores comunes del pacto constitucional le corresponde su defensa y promoción, aspectos respecto de los cuales profundizaré más adelante.

\section{Libertad de conciencia y sociedades multiculturales: ¿igual valor para todas las culturas?}

El término multiculturalismo hace referencia a un datum fáctico relativo a la convivencia en un mismo país o región de tradiciones culturales distintas ${ }^{27}$.

La relación entre la cultura y la libertad de conciencia es bastante estrecha ya que en la formación de la conciencia identitaria personal, la cultura del medio social desempeña un papel relevante al "proveer a sus miembros de modos de vida que tienen sentido y que abarcan el rango completo de sus actividades humanas, tanto en la esfera pública como privada" 28 .

26. LLAMAZARES, Dionisio: Derecho de la Libertad de Conciencia, ob., cit. Págs. 350-351.

27. FERNÁNDEZ, Eusebio, ob., cit. Pág. 67.

28. OLIVÉ, León: “Globalización y multiculturalismo”, en Multiculturalismo y pluralismo, Paidós, México, 1999. Pág. 43.

Facultad de Derecho y Ciencias Sociales - Universidad de Valparaíso - Chile 
Así entendido, la cultura es un entramado complejo que incluye conocimientos, creencias, arte, moral, costumbres y cualesquiera otros hábitos que expresan una determinada forma y modo de comprensión e interpretación del mundo y de la posición del individuo dentro de la comunidad. Dicho en esa forma, la cultura presenta una dimensión normativa acerca de cuáles son las opciones de vida posibles y aceptadas dentro de una colectividad. Con lo cual, la existencia de diferentes culturas al interior de una sociedad implica, entonces, aceptar que cada una cumple un "papel similar al de una teoría de la justicia, al de una teoría ética o al de una teoría política, al igual que lo hacen las teorías de los derechos" 29 .

Dicho así, la multiculturalidad en una sociedad democrática incuba el germen de la conflictividad social, con una alta probabilidad de falta de coincidencia y comprensión entre las distintas culturas que comparten un mismo ámbito espacial sea entre la cultura dominante y las minoritarias o las no dominantes entre sí.

Lo anterior es causa de numerosas interrogantes: ¿cómo se abordan los conflictos sociales derivados de multiculturalidad? ¿hasta dónde se puede llegar en el respeto de las particularidades culturales de la población inmigrante como correlato de la libertad de conciencia? ¿es posible valorar las distintas culturas?

Las peguntas anteriores plantean la legítima inquietud acerca de si la observancia de la libertad de conciencia en contextos multiculturales, equivale a tener que aceptar la inexistencia de una moral crítica universal conforme a la cual pueda ser realizada una valoración de las distintas culturas. Y, en consecuencia, todas las culturas tendrían la misma valoración ya que sus prácticas deberían ser examinadas en conformidad a las creencias, valores, normas, costumbres e intereses de la respectiva tradición cultural.

La verdad es que me surgen serias dudas y aprehensiones, en aceptar un supuesto igual valor de las distintas morales particulares derivadas de los contextos culturales. La sola posibilidad conduce a una

29. DE ASÍS, Rafael: "Derechos Humanos: integración y diferenciación”, en Marcos del Cano, Ana María (coordinadora), Inmigración, multiculturalismo y derechos humanos, Tirant lo Blanch, Valencia, 2009, Pág. 49.

Revista de Ciencias Sociales - Número 63 (2013) - Universidad de Valparáíso - ISSN 0716-7725-Valparáiso, Chile 
disolución de la idea de universalidad de los derechos humanos que, en buena parte de las sociedades occidentales, ha sido incorporada como un mínimo común denominador ético inderogable e imprescindible para una convivencia racional y razonable.

Lo anterior ha sido objeto de una abierta discrepancia, entre las posiciones universalistas que defienden la existencia de criterios racionales que permiten valorar positiva o negativamente a una cultura respecto a otra, y aquellas denominadas relativistas que abogan por la falacia del universalismo y por el igual valor de todos los referentes éticos particulares de un determinado medio cultural.

Las posiciones absolutistas consideran que a pesar de la diversidad cultural existen unos "principios que cualquier persona debería aceptar sea cual sea su contexto cultural, con tal que los examine racionalmente y sin prejuicios" ${ }^{30}$. Es una defensa a una moral crítica constituida por una malla axiológica que sería universal por constituir expresión de una racionalidad mínima e independiente del colectivo cultural en que se encuentre inmersa una persona. De lo anterior se desprende que, el absolutismo niega la posibilidad desde la perspectiva ética, de asignar valor equivalente a las distintas morales positivas propias de cada tradición cultural, y, por ende, deben ser rechazadas aquellas que no respeten los presupuestos de racionalidad dados por la citada ética crítica universal.

El absolutismo aparece vinculado con posiciones ideológicas cercanas al liberalismo, según las cuales la organización política se constituye a partir de un sujeto abstracto desligado de toda consideración particular relacionada con su sexo, raza, religión, ideología, etc., donde solamente tienen importancia aquellos "rasgos que toda persona tiene en común y que son compartidos universalmente, esto es, su igual dignidad y respeto por su autonomía moral”31.

30. OLIVÉ, León: “Multiculturalismo”, en Multiculturalismo y pluralismo, Paidós, México, 1999. Pág. 46.

31. VALLESPÍN, Fernando: "Democracia, pluralismo y diversidad”, en Diego Bermejo (Ed.), La identidad en sociedades plurales, Anthropos, Barcelona, 2011. Pág. 181.

Facultad de Derecho y Ciencias Sociales - Universidad de Valparaíso - Chile 
El respeto a la dignidad y la libertad individual son los parámetros conforme a los cuales el liberalismo entiende que son los límites al respeto e igual valoración de las otras culturas (figurativamente hablando). Así entendido, el presupuesto básico del liberalismo es que toda persona tiene derecho a organizar su vida según los dictados de su conciencia autónoma y responsable, lo que impone al Estado la exigencia de guardar una exquisita neutralidad ideológica basa en la observancia de una igualdad formal y abstracta.

Sin embargo, y como consecuencia del contexto multicultural de las sociedades contemporáneas, una parte de la teoría liberal atribuye importancia a la cultura en el proceso de construcción identitaria del individuo, superando la posición clásica anclada en concepción abstracta de persona que lo despoja de sus condiciones y circunstancias particulares, entre ellas, su medio de socialización cultural. La idea central es que el reconocimiento de la autonomía y el valor del individuo, entendida como ejercicio de la libertad básica de elegir sus opciones y planes de vida, sigue siendo piedra angular del liberalismo pero, entiende que deben preservarse y garantizarse los elementos culturales puesto que en ellos la persona encuentra y despliega sus opciones y planes vitales $^{32}$.

No obstante, la relevancia que se le reconoce a la cultura en el desenvolvimiento de la autonomía moral individual, el liberalismo se decanta por la prioridad del individuo sobre el colectivo, lo que se traduce en un límite interno para el colectivo cultural respecto al abanico de legitimidad de las medidas que puede imponer el grupo fundado en el acervo cultural. La pluralidad cultural no puede fagocitar el valor de la dignidad y la autonomía moral.

En las antípodas de las posiciones liberales están las de tipo comunitaristas quienes frente a la diversidad cultural abogan por una apología al relativismo cultural. Si bien existe coincidencia con el liberalismo multicultural respecto a la importancia del medio cultural en la construcción de la identidad personal, rechazan la existencia de criterios universales de racionalidad conforme a los cuales pueda ser evaluada moralmente una cultura, por el contrario consideran que cada

32. Ibídem. Pág. 186.

Revista de Ciencias Sociales - Número 63 (2013) - Universidad de Valparaíso - ISSN 0716-7725-Valparaíso, Chile 
cultura debe ser examinada en función de su particular sistema de creencias, valores y normas.

Sin embargo, el presupuesto del relativismo: todas las culturas valen lo mismo, se funda en la presunción de que todas las culturas han producido algo valioso para la humanidad o, dicho de otra manera, contribuyen a su enriquecimiento. Dicho punto de partida devela más problemas que soluciones, ya que implica preguntarse si es una presunción a priori o expuesta a refutación posterior. Si la presunción es a priori significa que el relativismo incurriría en el mismo defecto que critica al liberalismo, ya que "presupone en los seres humanos la capacidad de reconocer verdades a priori entendidas como absolutas y universales" ${ }^{\prime 3}$. Y, también, si la citada presunción admite prueba en contrario implicaría aceptar para el relativismo que, eventualmente, una cultura no tiene nada de valioso para la humanidad ergo es inferior respecto de las otras.

El problema del relativismo ha sido, certeramente, desnudado por el profesor Ernesto Garzón Valdés, quien si bien considera un bien positivo la preocupación por la diversidad cultural estima que existe una sobrevaloración de su salvaguarda centrada en considerar en sí misma la pluralidad cultural, lo que puede conducir a problemas de orden moral como la protección y estímulo de fundamentalismos religiosos que son, claramente, contrarios a los derechos humanos y a los valores del pluralismo y tolerancia. Considera que esta tendencia se debe a confusiones conceptuales y que agrupa en cinco: 1.- confusión entre tolerancia y relativismo moral; 2.- confusión entre diversidad cultural y enriquecimiento moral; 3.- confusión entre identidad personal e identidad social; 4.- confusión entre unidad cultural y unidad institucional; y 5.- confusión entre sujetos jurídicos y sujetos morales ${ }^{34}$.

En lo que dice relación con la supuesta presunción del enriquecimiento que para la humanidad supone la protección y respeto de toda diversidad cultural, me interesa la segunda confusión. Puesto

33. OLIVÉ, León, ob., cit. Pág. 78.

34. GARZÓN, Ernesto: "La pretendida relevancia moral de la diversidad cultural”, en Calamidades, Gedisa, Madrid, 2004, pp. 94-95.

Facultad de Derecho y Ciencias Sociales - Universidad de Valparaíso - Chile 
que, ella se funda en una falacia al vincular diversidad con enriquecimiento de posibilidades morales de desenvolvimiento individual y colectivo, según Ernesto Garzón:

"No entiendo cuál puede ser la contribución del enriquecimiento moral de la práctica por ejemplo, de la circuncisión femenina prescrita en diversos países de África al norte del ecuador como una vital tradición cultural; de la quema de viudas en la India; de la discriminación sistemática de la mujer; de la costumbre de los de sacrificios humanos o de la imposición absoluta de los padres en la elección del cónyuge de sus hijas con la consecuencia de que $<<$ al casarse con alguien a quien no conocen se ven expuestas a recibir golpizas que les propinan sus maridos escogidos por sus padres $>>$, para usar una plástica descripción de esta costumbre recogida por el jurista mexicano Lisandro Cruz Ponce en un estudio sobre la organización familiar indígena" ${ }^{35}$.

Agregaría que, también me es difícil y hasta irracional pretender reconocer igual valor e importancia a la práctica cultural que elimina y diezma en conductas abiertamente genocidas a poblaciones en razón de su pertenencia a una etnia determinada, o de aquellas que legitiman castigos inhumanos y degradantes tales como la lapidación de las adúlteras o de la pena de latigazos o muerte a las mujeres violadas.

De lo anteriormente expuesto, es posible colegir la imposibilidad de atribuir a una tradición cultural valor ético, por el hecho de ser tal, tal como lo postula el relativismo cultural. El principal peligro de esa tesis es que inmuniza a cualquier colectivo cultural de ser evaluado en términos éticamente desfavorables, ya que todas valdrían lo mismo, con lo cual las prácticas o conductas que pueden ser consideradas aborrecibles o monstruosas para la condición humana siempre encontrarían justificación, acomodo y razonabilidad, pues su examen se remite al acervo axiológico y antropológico de la respectiva tradición cultural.

Pero, lo que es peor, drena de contenido a la idea de la dignidad humana, fundamento filosófico de los derechos humanos y, asimismo, la noción de su violación quedaría supeditada a las múltiples concepciones culturales locales o regionales, disolviendo la pretensión

35. Ibídem. Págs. 100-101

Revista de Ciencias Sociales - Número 63 (2013) - Universidad de Valparáíso - ISSN 0716-7725-Valparáiso, Chile 
de universalidad del valor intrínseco del ser humano ligada al reconocimiento de ciertos derechos esenciales que, parece difícil diluir en el respeto de la realidad multicultural.

Llegado a este punto, es importante recordar que la aprobación de la Declaración Universal de los Derechos Humanos, sin duda representa un paso gigantesco para la civilización, ya que es un consenso sobre ciertos derechos que se consideran esenciales y logran convocar la aceptación de un amplio espectro de ideologías políticas, filosóficas y tradiciones culturales, estableciendo un mínimo ético común basado en la reivindicación de que todo ser humano es titular de unos derechos básicos que son expresión de exigencias morales derivadas de la dignidad de la persona.

Así entendido, la idea común de los derechos humanos, difícilmente, puede ser desechada sin más, bajo el pretexto de ser una invención e imposición de un modelo moral de la cultura occidental, como suelen afirmar las corrientes del relativismo moral. Sí, por cierto que los derechos humanos es un invención —entendida como conquista de la humanidad - que reivindica una condición común del ser humano, su derecho a tener derechos, lo que le da cierta condición de preferencia respecto a otras ideologías. De modo que, en sentido metafórico el diálogo entre las distintas tradiciones culturales debe serlo con todas, y aquellas que rechacen este mínimo común denominador ético deben entrar en el terreno de la discusión racional y explicar el por qué de su actitud ${ }^{36}$. No pueden demandar la aceptación de valor ético de su ideología o creencia cultural, por la sola condición de ser diversa.

En síntesis, el multiculturalismo relativista desafía a la idea moral fundamental y universal encapsulada en los derechos humanos, explicitada en el preámbulo de la Declaración Universal y que, con motivos de los numerosos movimientos migratorios, afecta particularmente, a las sociedades occidentales de tradición liberal y democrática cuyos principios generales y políticos están anclados en la importancia de los derechos humanos, según lo expresan en sus constituciones, leyes, y en los tratados internacionales incorporados a

36. FERNÁNDEZ, Eusebio, ob., cit. Pág. 61.

Facultad de Derecho y Ciencias Sociales - Universidad de Valparaíso - Chile 
su Derecho interno. Problemática que obliga a buscar un modo de conciliar la idea de universalidad de los derechos humanos, entre ellos la valía de la libertad de conciencia, y el respeto de las particularidades culturales como rasgo relevante de la formación de la conciencia individual.

Aunque, sí parece claro que hay un límite a la tolerancia cultural como tributo al pluralismo de las democracias, en cuanto que aquellos que no están dispuestos a respetar el valor de la tolerancia y los derechos humanos, en pos de mantener sus costumbres, incluso desafiando los principios, valores y leyes fundamentales de la sociedad, no pueden estar en condiciones de exigir tolerancia. La tolerancia es un valor de la democracia, pero no puede transformarse en su autodestrucción. El precio de la tolerancia cultural y de la convivencia en un medio multicultural, no puede significar el abandono, renuncia o siquiera relativización de la universalidad de los derechos humanos, según defiendo a continuación.

\section{La universalidad de los derechos humanos: límite a la diversidad cultural de la libertad de conciencia}

De acuerdo con lo ya expuesto, en las sociedades democráticas multiculturales, no es posible aceptar que todas las éticas identificadas con un modo cultural valgan lo mismo, atendido que la cohesión social en una democracia depende de la adhesión activa a la ética pública representada por el ideal de los derechos humanos. El ethos de la democracia condiciona el respeto y promoción de la seña de pluralidad cultural a su coherencia con ella, ya que es un mínimo moral que no es susceptible de transacción en aras de las particularidades culturales. Es una opción de valor que hunde sus raíces, en la convicción sobre la universalidad de aquellas condición morales de la Humanidad, expresadas en los derechos humanos fundamentales que se colocan por sobre cualquier especificidad de un determinado código cultural.

La universalidad de los derechos humanos no es un impedimento al pluralismo cultural dentro de una sociedad, ni menos una imposición cultural de occidente en desmedro de otras visiones sobre la dignidad y los derechos humanos, atendido que la universalidad no es sinónimo

Revista de Ciencias Sociales - Número 63 (2013) - Universidad de Valparáíso - ISSN 0716-7725-Valparáiso, Chile 
de uniformidad de comprensión de los derechos humanos sino que su pretensión es más modesta, pero no menos importante: contribuir a fijar un marco común ético de argumentación que limite la dinámica del debate público de las sociedades en contexto de diversidad cultural. Lo que está en absoluta sintonía con la aspiración de la Declaración Universal cuyo preámbulo concibe a los derechos contenidos en ella como un ideal común por el que los pueblos y naciones deben esforzarse.

El ideal común de los derechos humanos es nada menos que un consenso acerca de la necesidad de establecer un mínimo común denominador ético y, agrego, de racionalidad para el desarrollo y desenvolvimiento de una convivencia pacífica entre ethos individuales o de colectivos culturales diferentes. Es un acuerdo fundado en la convicción de que todo ser humano racional debe aceptar dos proposiciones centrales: el derecho a la autodefensa y la prohibición de dañar a otro arbitraria o innecesariamente a sus semejantes, ya que si los miembros de una sociedad renuncian al primero de los principios cualquier psicópata podría destruirla y si se permite que cualquiera pueda tratar a los demás como si fueran árboles o animales inferiores, está condenada a desaparecer ${ }^{37}$.

Dicho de ese modo, la universalidad de los derechos humanos es una apología a un sentido mínimo e irreductible para el lenguaje de los derechos humanos, que se remite a la reivindicación del valor intrínseco de la dignidad de la persona, pues es un rasgo compartido por y entre todos los seres humanos.

En ese orden de ideas, el camino iniciado con la aprobación de la Declaración Universal, expresa una idea de civilización con un firme compromiso moral — derechos humanos-que necesariamente "relativiza el valor de la propia cultura y la somete a las exigencias objetivas de los derechos universales lo que permite que todas las culturas puedan ser examinadas y valoradas por su aproximación a ese ideal civilizador" ${ }^{\prime 3}$. Así expuesto, la diversidad cultural en una sociedad

37. GARZÓN, Ernesto, ob., cit. Pág. 99.

38. FERNÁNDEZ, Eusebio: "La idea de Europa en Europa y los derechos humanos”, en Dignidad humana y ciudadanía cosmopolita, Dykinson, Madrid, 2001. Pág. 54.

Facultad de Derecho y Ciencias Sociales - Universidad de Valparaíso - Chile 
democrática es un rasgo positivo que esta en consonancia con su valor del pluralismo, pero puede ser un factor negativo cuando la particularidad de una práctica cultural, es irreconciliable con la dignidad humana y sus derechos.

El ideal común de los derechos humanos, entonces, representa una ética pública de mínimos que se corresponde con la defensa y promoción de las condiciones morales esenciales identificadas con la Humanidad y que impiden rebajar y tratar a la persona como un medio, instrumento o cosa. Así mismo, sienta las bases para el libre y pleno desarrollo de la personalidad en el respeto y aceptación de las diferencias de una sociedad plural. El reconocimiento y respeto de las condiciones morales propias de la Humanidad, evoca un compromiso por el respeto al derecho a la vida, integridad física y moral, y a la libertad de autodeterminación, como núcleo indeleble de la dignidad de la persona humana y base necesaria para el ejercicio y desarrollo del resto de los derechos fundamentales.

La identificación de la ética pública de mínimos con el lenguaje de los derechos humanos y con los valores que encarna la democracia -respeto y alta valoración de las diferencias: pluralismo, preferencia por la adhesión moral de las decisiones que son resultado del diálogo y acuerdos- que están incorporados en los textos fundamentales de las democracias liberales, revela una dimensión moral del pacto social que, difícilmente, puede ser aceptado que sea derogado por un supuesto derecho ilimitado a vivir según las convicciones particulares.

Por su parte, la defensa y promoción que al Estado le corresponde de esta ética pública, no resulta contradictoria con la libertad de conciencia, ni con la neutralidad ideológica que éste debe observar, ya que se trata de una ética sobre principios y valores que son el sostén del orden social — de ahí el adjetivo de mínimos — reconocidos en la constitución y derecho internacional sobre derechos humanos. Siendo lícito y legítimo que puedan ser interpelados como valores comunes de obligatorio respeto por todos, sin que puedan ser desconocidos por las diversas éticas privadas. Puesto que, además, son esos valores comunes los que sirven de presupuesto a los derechos y libertades así como a la emancipación de cada individuo en sus valores diferenciales.

Revista de Ciencias Sociales - Número 63 (2013) - Universidad de Valparáíso - ISSN 0716-7725-Valparáiso, Chile 
El compromiso del Estado con la ética pública de mínimos, tampoco, supone, necesariamente, la inexistencia de un espacio público para el reconocimiento de un derecho a la diferencia y a la participación política y social, para los distintos grupos culturales que conviven en el seno de una sociedad, en correlato directo a la libre formación y expresión de la conciencia. Asimismo, nada impide que los valores diferenciales de las culturas, en el marco del diálogo y encuentro entre los miembros y/o colectivos culturalmente diferentes puedan, en el respeto de las reglas del juego democrático, acabar siendo incorporados en los valores comunes. Pero, ante todo resulta esencial que en la relación entre la multiculturalidad y la libertad de conciencia, se anteponga el respeto de los valores de racionalidad ética mínima universal representada por la dignidad humana y los derechos humanos.

De acuerdo con lo ya expuesto, es posible afirmar que los derechos humanos, son expresión de una constitución moral común que está por sobre los argumentos del respeto a la diferencia de una determinada tradición cultural, pero sin llegar a ser una posición incompatible con la reivindicación de las particularidades de los distintos modus vivendi de cada tradición cultural.

El respeto a la diferencia cultural no está condicionada a rechazar de plano la universalidad de los criterios morales subyacentes en los derechos humanos. La incompatibilidad absoluta de la particularidad con la universalidad, en términos de: es lo uno o lo otro, representa un falso dilema, ya que la convivencia pacífica y armoniosa de diversos grupos colectivos requiere de normas morales que permitan superar las contradicciones, fisuras y conflictos dado por la disparidad de tradiciones y valores culturales.

Por lo demás, cuando menos merece ser mirada con cierta desconfianza la defensa que, en las conferencias sobre derechos humanos, se hace sobre una pretendida preeminencia de las tradiciones culturales nacionales o regionales, tanto porque es un ataque directo a la aspiración ética encarnada en la Declaración Universal como, también, porque normalmente son críticas que provienen de países con dudosas credenciales en el respeto de los derechos humanos básicos y de los valores democráticos — estados africanos, asiáticos y del Islamcuya ideología política está sustentada en la negación e incompatibilidad del ethos de la dignidad humana.

Facultad de Derecho y Ciencias Sociales - Universidad de Valparaíso - Chile 
Así, en la Declaración de Túnez, aprobada el 6 de noviembre de 1992, los Estados africanos a pesar de reconocer la universalidad de los derechos humanos, proclamaron que:

"No puede prescribirse un modelo determinado a nivel universal ya que no pueden desatenderse las realidades históricas y culturales de cada nación y las tradiciones, normas y valores de cada pueblo".

Asimismo, los Estados asiáticos en la Declaración de Bangkok, de 23 de abril de 1993, manifestaron que si bien los derechos humanos son universales:

"Deben considerarse en el contexto de un proceso dinámico y evolutivo de fijación de normas internacionales, teniendo presente la importancia de las particularidades nacionales y regionales y los diversos antecedentes históricos, culturales y religiosos”.

La Declaración de los Derechos Humanos en el Islam, o, también conocida como la Declaración de El Cairo, de 5 de agosto de 1990, según la cual los derechos humanos reconocen como fuente principal la Sharia o Ley islámica, significa borrar la universalidad moral contenida en la Declaración Universal, reemplazándola por el relativismo cultural del Islam.

La importancia de rescatar la universalidad de la moral crítica consagrada en los derechos humanos, radica en excluir de la diversidad cultural la observancia de las exigencias morales mínimas contenidas en estos, como expresión del valor universal de la dignidad, y, al mismo tiempo, reconoce la importancia de las diferencias culturales como referentes primarios de formación de la conciencia individual ergo de su identidad personal pero siempre en un plano subordinado al ethos mínimo.

La Conferencia Mundial de los Derechos Humanos en su Declaración y Programa de Acción, de 25 de junio de 1993, confirma la compatibilidad de la universalidad con la diversidad cultural, con preferencia de la primera señalando:

"La Conferencia Mundial de Derechos Humanos reafirma el solemne compromiso de todos los Estados de cumplir sus obligaciones de promover el respeto universal, así como la observancia y protección de todos los derechos

Revista de Ciencias Sociales - Número 63 (2013) - Universidad de Valparáíso - ISSN 0716-7725-Valparáiso, Chile 
humanos y de las libertades fundamentales de todos de conformidad con la Carta de las Naciones Unidas, otros instrumentos relativos a los derechos humanos y el derecho internacional.

El carácter universal de esos derechos y libertades no admite dudas.

En este contexto, el fortalecimiento de la cooperación internacional en la esfera de los derechos humanos es esencial para la plena realización de los propósitos de las Naciones Unidas.

Los derechos humanos y las libertades fundamentales son patrimonio innato de todos los seres humanos; su promoción y protección es responsabilidad primordial de los gobiernos.

Todos los derechos humanos son universales, indivisibles e interdependientes y están relacionados entre sí. La comunidad internacional debe tratar los derechos humanos en forma global y de manera justa y equitativa, en pie de igualdad y dándoles a todos el mismo peso. Debe tenerse en cuenta la importancia de las particularidades nacionales y regionales, así como de los diversos patrimonios históricos, culturales y religiosos, pero los Estados tienen el deber, sean cuales fueren sus sistemas políticos, económicos y culturales, de promover y proteger todos los derechos humanos y las libertades fundamentales".

De lo anterior se puede colegir que, la multiculturalidad impone a las sociedades democráticas el desafío de replantear la idea de universalidad a partir de la diferencia, Gurutz Jáuregui lo sintetiza certeramente:

“Todo ello nos lleva a confirmar que la coexistencia de particularidades no es posible sin la existencia de valores universales compartidos, sin un sentido de pertenencia a la comunidad más amplio que el de los grupos particulares en cuestión y viceversa. En definitiva lo universal emerge de lo particular, no tanto como un principio que fundamenta y explica lo particular, sino como un horizonte incompleto que sutura la identidad dislocada...La humanidad no debe configurar tanto valores universales detallados, cando un mínimo imprescindible sin el que las sociedades difícilmente podrían sobrevivir" ${ }^{39}$.

39. JÁUREGUI, Gurutz, ob., cit. Págs. 284-285.

Facultad de Derecho y Ciencias Sociales - Universidad de Valparaíso - Chile 
La reivindicación de la universalidad de los derechos humanos como una ética de mínimos escenifica la sutura del mosaico cultural, ya que el carácter sagrado de la vida, la dignidad humana y la importancia de la justicia, son temas recurrentes en todas las culturas y en todas las tradiciones filosóficas y religiosas. Todo lo cual implica reconocer que si los derechos humanos son una creación de la cultura de occidente, pero ello no conlleva negar su universalidad: la terminología puede ser específica de una cultura, pero los principios no ${ }^{40}$.

\section{Conclusiones}

1. El derecho a la libertad de conciencia exhibe una relación estrecha con la dignidad de la persona humana. Pues, es un derecho fundamental vinculado con la facultad más íntima y propia del ser humano: su capacidad y autonomía para decidir quién ser y cómo relacionarse con los demás y el mundo.

2. En el proceso de formación de la conciencia e identidad personal, tiene importancia el referente cultural de la sociedad donde el individuo se desarrolla y relaciona con los demás. La cultura expresa un conjunto de creencias que expresa una determinada concepción de los derechos y la justicia, derivándose una serie de prescripciones éticas que condicionan la extensión del margen de opciones y planes de vida que la persona puede elegir y emprender. De modo que, la cultura influye en la construcción de la conciencia personal pero, también, dota al individuo de un sentimiento de pertenencia con una identidad y cosmovisión común representada por un colectivo.

3. Dado lo anterior, la identidad personal, no es fruto del ejercicio del libre albedrío en medio de un páramo de creencias. La construcción de los rasgos de la personalidad es consecuencia, por cierto, del uso de la facultad de autodeterminación pero inmerso en un contexto cultural. Así entendido, el reconocimiento de la especificidad cultural como rasgo de la identidad personal, obliga a las sociedades receptoras

40. CARRILLO-SALCEDO, Juan Antonio: "El problema de la universalidad de los derechos humanos en un mundo único y diverso”, en Rodríguez Palop, $\mathrm{M}^{\mathrm{a}}$. Eugenia, y Tornos, Andrés (eds.), Derechos culturales y derechos humanos de los inmigrantes, Universidad Pontificia Comillas, Madrid, 2000. Pág. 51.

Revista de Ciencias Sociales - Número 63 (2013) - Universidad de Valparáíso - ISSN 0716-7725-Valparaíso, Chile 
de inmigración a respetar el derecho humano básico y esencial de: ser quién eres y de actuar como tal.

4. Las exigencias que impone la libertad de conciencia son una necesidad urgente de satisfacer, en las democracias liberales que albergan una multiplicidad de colectivos culturales con motivo, en la gran mayoría de los casos, de la ingente inmigración. Siendo, por tanto, la multiculturalidad un desafío porque el pluralismo es una de las señas de identidad de la democracia. Sin que sea posible argumentar el rechazo a priori del ejercicio de la libertad de conciencia de los inmigrantes en su dimensión externa.

5. Sin embargo, la elasticidad de la democracia en la aceptación de la diferencia cultural no puede ser ilimitada, ya que no parece razonable que incluso haya que dispensar respeto, conforme a los valores de la laicidad, tolerancia y pluralismo, hacia aquellas ideologías que promueven un signo contrario al ethos democrático. La democracia tiene el deber de protegerse a sí misma pudiendo exigir que todos compartan los valores comunes que permiten una cohesión social en torno a un mínimo común denominador ético público, sin que ello signifique una renuncia a la identidad cultural.

6. La elasticidad limitada de la democracia para la aceptación de la diferencia cultural se explica, también, porque un valor material de ella consiste en su compromiso con el respeto a los derechos humanos. Característica de la democracia que la acerca al debate actual respecto a la relación entre la universalidad de los derechos humanos y la especificidad cultural, decantándose por una preferencia hacia la universalidad de los derechos humanos sobre la particularidad de una tradición cultural.

No es una opción que excluya las identidades culturales en pos de la universalidad de los derechos humanos, como suele ser presentado por los países asiáticos, africanos y del Islam. Sino que se trata de una preferencia que adhiere a la convicción sobre la posibilidad de coexistencia de la universalidad de los derechos humanos con las particularidades culturales. Pero, en ella el universalismo ocupa el lugar de un marco mínimo de argumentación que impide relativización de la Humanidad y sus condiciones morales básicas y esenciales.

Facultad de Derecho y Ciencias Sociales - Universidad de Valparaíso - Chile 
Si un grupo cultural estima que la ética de los derechos humanos contenida en la Declaración Universal, es incompatible con el respeto de las tradiciones culturales y la libertad de conciencia, tendrá que ingresar al terreno de la argumentación, sin que baste exclusivamente enarbolar la bandera de la especificidad cultural. Puesto que, las exigencias morales contenidas en los derechos humanos de la Declaración Universal, se relacionan con aspectos nucleares de la Humanidad cuya controversia y desplazamiento en pos de la particularidad cultural parece difícil. En especial, porque éstos encarnan un avance civilizador de la Humanidad basado en el respeto del valor intrínseco de la vida humana.

7. La defensa de un sentido mínimo de los derechos humanos que escapa a la diversidad cultural, se corresponde con un rechazo al relativismo cultural y su presupuesto de que todas las formas culturales valen lo mismo. En efecto, los derechos humanos expresan criterios morales universales que sirven como moral crítica para valorar favorable o desfavorablemente, la ética de una determinada tradición cultural. Lo que a la postre tiene importancia para la gestión de la diversidad cultural en las sociedades democráticas multiculturales, pudiendo legítimamente una democracia rechazar aquellas formas de vida social incompatibles con los derechos y libertades individuales, sin que por ello sea una violación de la libertad de conciencia.

\section{Bibliografía}

\section{Libros y artículos}

CARRILLO-SALCEDO, Juan A.: "El problema de la universalidad de los derechos humanos en un mundo único y diverso", en Rodríguez Palop, Ma . Eugenia, y Tornos, Andrés (eds.), Derechos culturales y derechos humanos de los inmigrantes, Universidad Pontificia Comillas, Madrid, 2000.

DE ASÍS, Rafael: "Derechos Humanos: integración y diferenciación”, en Marcos del Cano, Ana María (coordinadora), Inmigración, multiculturalismo y derechos humanos, Tirant lo blanch, Valencia, 2009.

Revista de Ciencias Sociales - Número 63 (2013) - Universidad de Valparáíso - ISSN 0716-7725-Valparáiso, Chile 
DE LUCAS, Javier: "Multiculturalidad e inmigración: la política de igualdad”, en Álvarez Yágüez, Jorge y Lago Peñas, Santiago (eds.), La convivencia plural: derechos y políticas de justicia, Ediciones Bellaterra, Barcelona, 2009.

FERNÁNDEZ, Eusebio:

- "La declaración de 1948. Dignidad humana, universalidad de los derechos y multiculturalismo", en Dignidad humana y ciudadanía cosmopolita, Instituto de Derechos Humanos Bartolomé de las Casas, Dykinson, Madrid, 2001.

- "La idea de Europa en Europa y los derechos humanos", en Dignidad humana y ciudadanía cosmopolita, Dykinson, Madrid, 2001.

- "El patriotismo constitucional", en Valores constitucionales y derecho, Dykinson, Madrid, 2009.

GARZÓN, Ernesto: "La pretendida relevancia moral de la diversidad cultural", en Calamidades, Gedisa, Madrid, 2004.

JÁUREGUI, Gurutz: "Inmigración y diversidad cultural en la era de la globalización. De la multiculturalidad a la interculturalidad", en Alberdi Bidaguren, Jokin y Goizueta Vértiz, Juana (coords.), Algunos retos de la inmigración en el siglo XXI, Marcial Pons, Madrid, 2008.

KANT, Immanuel: La metafísica de las costumbres, Madrid, Tecnos, 1994, (traducción Adela Cortina y Jesús Conill).

KYMLICKA, Will: "La educación para la ciudadanía”, en La política vernácula. Nacionalismo, multiculturalismo y ciudadanía, Paidós,

Barcelona, 2003, traducción de Tomás Fernández Auz y Beatriz Eguibar.

LEMA, Margarita: Laicidad e integración de los inmigrantes, Marcial Pons, Madrid, 2007.

LLAMAZARES, Dionisio:

- Derecho de la libertad de conciencia, Vol I, Cuarta Edición, Thomson-Reuters, Madrid, 2011.

- Derecho de la libertad de conciencia, Vol II, Tercera Edición, Thomson-Civitas, Madrid, 2007.

- Educación para la ciudadanía democrática y objeción de conciencia, Colección Conciencia y Derecho, Dykinson, Madrid, 2010.

Facultad de Derecho y Ciencias Sociales - Universidad de Valparaíso - Chile 
OLIVÉ, León: "Globalización y multiculturalismo", en Multiculturalismo y pluralismo, Paidós, México, 1999.

PRIETO, Luis: "La libertad de conciencia”, en Constitución y Derechos Fundamentales, Centro de Estudios Políticos y Constitucionales, Madrid.

SARTORI, Giovanni, La sociedad multiétnica. Pluralismo, multiculturalismo, extranjeros e islámicos, Taurus, Madrid, 2003.

VALERO, Ana: Libertad de conciencia, neutralidad del Estado y principio de laicidad (un estudio constitucional comparado, Ministerio de

Justicia (Gobierno de España), Madrid, 2008.

VALLESPÍN, Fernando: "Democracia, pluralismo y diversidad, en Diego Bermejo (Ed.), La identidad en sociedades plurales, Anthropos, Barcelona, 2011.

\section{Documentos internacionales}

Comité de Ministros del Consejo de Europa, Recomendación $N^{o} 12$, sobre educación para la ciudadanía democrática, 16 de octubre de 2002, http://www..coe.int/t/dg4/education/.../2002_38_ Rec2002_ 12_Es.PDF

Declaración final de la reunión regional para África de la Conferencia Mundial de los Derechos Humanos, o, "Declaración de Túnez", 6 de noviembre 1992, los Estados africanos, http://www.un.org/es/ comun/docs/? symbol=A/CONF.157/PC/57

Declaración final de la reunión regional para Asia de la Conferencia Mundial de los Derechos Humanos o "Declaración de Bangkok", de 23 de abril de 1993, http://law.hku.hk/lawgovtsociety/ Bangkok\%20Declaration.htm

Declaración de los Derechos Humanos en el Islam, o, "Declaración de

El Cairo", de 5 de agosto de 1990, http://aministiacatalunya.org/ edu/docs/e-mes-islam-1990.html

Conferencia Mundial de los Derechos Humanos, Declaración y Programa de Acción, de 25 de junio de 1993, http://daccess-ddsny.un.org/d oc/UND OC/GEN/G93/142/36/PDF/ G9314236.pdf? OpenElement Organización de las Naciones Unidas, Declaración Universal de los Derechos Humanos, 10 de diciembre de 1948.

Revista de Ciencias Sociales - Número 63 (2013) - Universidad de Valparáíso - ISSN 0716-7725-Valparáiso, Chile 


\section{Jurisprudencia}

Comité de Derechos Humanos de las Naciones Unidas, Observación General 22, Sesión 48, 30 de julio 1993.

\section{Corte Europea de Derechos Humanos:}

Bayatyan c. Armenia, No 23.459/93, 7 de julio 2011.

Kokkinakis c. Grecia, No 14.307/88, 25 de Mayo 1993.

Buscarini y otros c. San Marino, No 24.645/94, 18 de febrero 1999.

Christine Goodwin c. Reino Unido, No28957/95, de 11 de julio 2002.

Leíla Sahin c. Turquía, asunto Nº44.774/98, de 10 de noviembre 2005, en su parágrafo 108.

Comisión europea de Derechos Humanos, Kuhnen c. República Federal de Alemania, No12194/86, 12 de mayo 1988.

Tribunal Constitucional español, Sentencia N²0/1990, de 15 de febrero, FJ $3^{\circ}$ y $4^{\circ}$.

Tribunal Constitucional español, Sentencia No53/1985, de 11 de abril, FJ $8^{\circ}$.

Facultad de Derecho y Ciencias Sociales - Universidad de Valparaíso - Chile 